University of Nebraska - Lincoln

DigitalCommons@University of Nebraska - Lincoln

Craig J. Eckhardt Publications

Published Research - Department of Chemistry

December 1977

\title{
Observation of Davydov splitting in PTS polydiacetylene crystal spectra
}

Hans Muller

University of Nebraska - Lincoln

Craig J. Eckhardt

University of Nebraska - Lincoln, ceckhardt1@unl.edu

Follow this and additional works at: https://digitalcommons.unl.edu/chemistryeckhardt

Part of the Chemistry Commons

Muller, Hans and Eckhardt, Craig J., "Observation of Davydov splitting in PTS polydiacetylene crystal spectra" (1977). Craig J. Eckhardt Publications. 37.

https://digitalcommons.unl.edu/chemistryeckhardt/37

This Article is brought to you for free and open access by the Published Research - Department of Chemistry at DigitalCommons@University of Nebraska - Lincoln. It has been accepted for inclusion in Craig J. Eckhardt Publications by an authorized administrator of DigitalCommons@University of Nebraska - Lincoln. 


\title{
LETTERS TO THE EDITOR
}

\author{
The Letters to the Editor section is subdivided into four categories entitled \\ Communications, Notes, Comments and Errata. The textual material of each Letter \\ is limited to 1200 words minus the following: (a) 200 words for a square figure \\ one-column wide. Larger figures are scaled in proportion to their area. (b) 50 \\ words for each displayed equation; (c) 7 words for each line of table including \\ headings and horizontal rulings. Proof will be sent to authors. See the issue of \\ 1 July 1977 for a fuller description of Letters to the Editor.
}

\section{Observation of Davydov splitting in PTS polydiacetylene crystal spectra ${ }^{\text {a) }}$}

\author{
Hans Müllerb) and Craig J. Eckhardt \\ Department of Chemistry, University of Nebraska, Lincoln, Nebraska 68588 \\ (Received 23 February 1977; revised paper received 22 September 1977)
}

The electronic spectra of polydiacetylene crystals have often been typified by poly-2, 4-hexadiyne-1, 6diol-bis-( $p$-toluene sulfonate) (PTS). The spectra of crystals of this polydiacetylene have been unique in that they have displayed a pronounced "doubling" of the $300 \mathrm{~K}$ spectral bands at temperature below $170 \mathrm{~K}$. The reflection bands are also observed to undergo a continuous red shift with continued decrease of temperature. The reflection band observed at lowest energy at $300 \mathrm{~K}$ is resolved at $77 \mathrm{~K}$ into two clearly separated bands at $15700 \mathrm{~cm}^{-1}$ (Ib) and $16050 \mathrm{~cm}^{-1}$ (IIb). ${ }^{1-5}$ A recent study by modulated piezoreflection spectroscopy on PTS crystals demonstrated that this "doubling" persists to 300 K. ${ }^{5}$ The phenomenon is best explained by recent $\mathrm{x}$-ray crystallographic studies which show that at $170 \mathrm{~K}$ the unit cell of the PTS doubles along the $c$ axis. ${ }^{6}$ This gives two pair of polymer chains in the low temperature unit cell which are translationally inequivalent and which sit at different sites. One pair is face centered while the other is located at the cell edges. This creates two energetically different environments for the different pairs and thus a splitting of the spectrum such as that actually observed may be expected. The existence of the doubling at $300 \mathrm{~K}$ may be attributed to persistence of the $170 \mathrm{~K}$ phase.

In contrast to the spectrum for light polarized along the polymer chain which lies parallel to the $b$ axis in the $P 2_{1} / c$ unit cell, ${ }^{7}$ that reported for the perpendicular direction in (001) showed a flat response. ${ }^{1}$ In the Frenkel exciton model of the PTS crystal, a Davydov split component would be expected with a polarization in the ac plane. ${ }^{8}$ The failure to detect a component polarized in the $a c$ plane would not necessarily be deemed unusual since the large interchain separation of $7.5 \AA$ could be expected to lead to a negligibly small crystal interaction. The lack of observation of such structure could be also completely rationalized by taking the transition moment to be polarized parallel to the $b$ axis and excluding vibrationally induced changes in polarization. To assure that no $a$-axis structure exists, an effort to locate such structure was made. This Com- munication reports the observation of $a$-axis polarized structure in the electronic spectrum of PTS.

Polarized normal incidence specular reflection spectra have been obtained for light polarized parallel and perpendicular to the chain direction and are shown in Fig. 1. In the $a$ axis $300 \mathrm{~K}$ spectrum a small broad peak is observed at $15900 \mathrm{~cm}^{-1}$ at a relative reflectivity of $7.65 \pm 0.05 \%$ which is only $0.5 \%$ above the background reflectivity. The $a$-axis piezoreflection ${ }^{9}$ spectrum at $300 \mathrm{~K}$ is shown over the region of interest. A definite change of slope is observed at $15950 \mathrm{~cm}^{-1}$.

At $77 \mathrm{~K}$ the $a$-axis structure is observed to red shift and become resolved. The lowest energy band at $300 \mathrm{~K}$ splits into two prominent peaks at 15650 (Ia) and 15870 (IIa) $\mathrm{cm}^{-1}$ and a weak peak at $16225 \mathrm{~cm}^{-1}$. ${ }^{10}$ The associated reflectivities are $7.1,6.4$, and $5.8 \%$ (all $\pm 0.1 \%$ ). Additional weak structure is observed at $16670,16850,17120$, and $17320 \mathrm{~cm}^{-1}$. The frequencies of the two prominent peaks are separated by $220 \pm 25$ $\mathrm{cm}^{-1}$ which is on the order of the separation indicated by the $300 \mathrm{~K}$ piezoreflection spectrum.

Measurements were obtained at $50 \mathrm{~cm}^{-1}$ intervals. The same frequencies were used for the scan in each spectrum. Data were obtained by ensemble averaging until a $95 \%$ confidence level was achieved. Spectra were taken from two different sets of crystals, ${ }^{11}$ each of which was photometrically aligned under crossed Glan-Thompson calcite prisms. The $300 \mathrm{~K}$ spectra were taken without windows between the sample and the reflectometer lens thereby establishing that the observed structure does not arise from external optical effects.

The pronounced peak occurring at $15900 \mathrm{~cm}^{-1}$ in the $a$-axis polarization may be assigned as the Davydov component of the $b$-axis $300 \mathrm{~K}$ polarized band. The piezomodulation spectrum of the $300 \mathrm{~K} a$-axis spectrum indicates structure at 15850 and $15970 \mathrm{~cm}^{-1}$. The apparent separation of these bands is only $120 \mathrm{~cm}^{-1}$ at room temperature. The lowest energy structure at $15830 \mathrm{~cm}^{-1}$ in the $300 \mathrm{~K} b$-axis piezomodulation spec- 


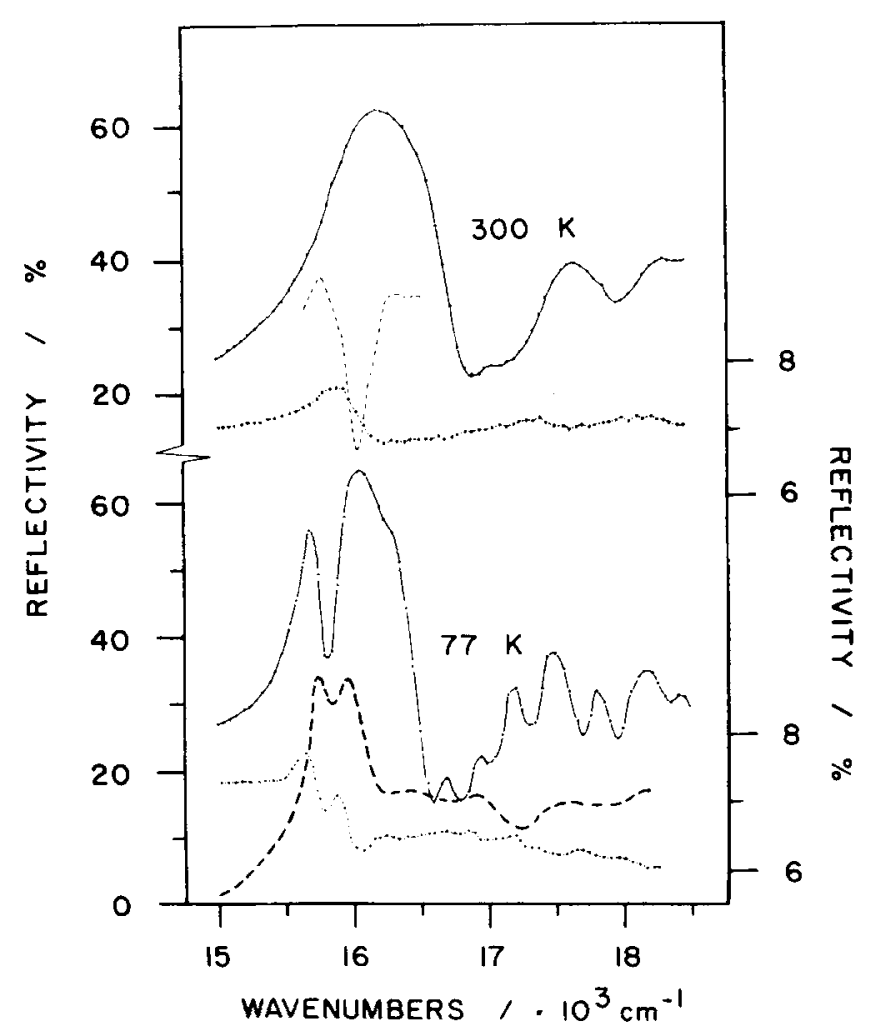

FIG. 1. Specular reflection spectra of PTS: $300 \mathrm{~K}$ spectra are displayed above the break in the ordinate; $b$-axis (upper curve, left ordinate), $a$-axis (lower curve, right ordinate), and $a$-axis piezoreflection (dashed line). $77 \mathrm{~K}$ spectra are shown below the break in the ordinate; $b$ axis (upper curve, left ordinate) and $a$ axis (lower curve, right ordinate). $\epsilon_{2}$ curve from Kramers-Krönig transform of $77 \mathrm{~K} b$-axis spectrum (heavy dashed line; arbitrary ordinate). Bandpass is 30 $\mathrm{cm}^{-1}$.

trum suggests a splitting which is on the order of the resolution of the experiment.

The $77 \mathrm{~K}$ data are more instructive. From the known energy of $\mathrm{Ib}$, the splitting for the lowest energy components is found to also be on the order of the resolution of the experiment. However, the apparent splitting between IIb and IIa is $180 \pm 25 \mathrm{~cm}^{-1}$. Comparison of the 77 and $300 \mathrm{~K} a$-axis spectra indicates that there is also significant thermal dependence of the intensities and frequencies of the $a$-axis system.

While splittings are apparent from the reflection spectra, meaningful values can only be obtained through Kramers-Krönig transforms of the reflection spectra. The transform of the $b$-axis reflection spectra have been previously reported and are in agreement with our trans- forms of the $b$-axis spectra. The $a$-axis spectra have also been transformed for both the 300 and $77 \mathrm{~K}$ spectra. For the $300 \mathrm{~K}$ spectrum a peak is observed in $\epsilon_{2}$ at $15840 \mathrm{~cm}^{-1}$ (b-axis) and $15940 \mathrm{~cm}^{-1}$ (a-axis) giving a Davydov splitting of $110 \mathrm{~cm}^{-1}$. At $77 \mathrm{~K}$ peaks in the $a-$ axis spectrum of nearly equal intensity appear at 15740 $\mathrm{cm}^{-1}$ (Ia) and $15940 \mathrm{~cm}^{-1}$ (IIa) whereas the peaks Ib and IIb appear with nearly equal intensities at 15600 and $15860 \mathrm{~cm}^{-1}$ in the $b$-axis polarization. Thus the $\mathrm{Ia}-\mathrm{Ib}$ splitting is $140 \pm 25 \mathrm{~cm}^{-1}$ and that for IIa-IIb is $80 \pm 25$ $\mathrm{cm}^{-1}$.

The dichroic ratios for both sets of peaks are $a / b$ $\sim 0.02$. This indicates a polarization of the transition of about $9^{\circ}$ off the $b$ axis which is similar to that found for the TCDU polydiacetylene crystal. ${ }^{12}$ It is also consistent with an excitonic model of the polymer. ${ }^{12,13}$

These data show that Davydov splittings do exist in the PTS crystal spectra in spite of the large interchain separation. While a satisfactory microscopic model for PTS does not yet exist, location of the Davydov components will necessarily affect current interpretations.

The authors thank Mr. Mark Jordan for assistance with the transforms.

${ }^{a}$ Supported by the Solid State Chemistry Program of the Division of Materials Research of the National Science Foundation (Grants DMR 75-01058 and 76-11634).

b) Fellow of the Deutsche Forschungsgemeinschaft.

${ }^{1}$ D. Bloor, D. J. Ando, F. H. Preston, and G. C. Stevens, Chem. Phys, Lett. 24, 407 (1974).

${ }^{2}$ B. Reimer, H. Bässler, J. Hesse, and G. Weiser, Phys. Status Solidi B 73, 709 (1976).

${ }^{3} \mathrm{D}$. N. Batchelder and D. Bloor, Chem. Phys. Lett, 38, 33 (1976).

${ }^{4}$ D. Bloor, F. H. Preston, and D. J. Ando, Chem. Phys. Lett. 38, 33 (1976).

${ }^{5}$ C. J. Eckhardt, H. Müller, J. Tylicki, and R. R. Chance, J. Chem. Phys. 65, 4311 (1976).

${ }^{6}$ V. Enkelman and G. Wegner, Makromol. Chem, 178, 635 (1977).

${ }^{7}$ D. Kobelt and E. F. Paulis, Acta. Crystallogr. Teil B 30, 232 (1973)

${ }^{8}$ A. S. Davydov, Theory of Molecular Excitons (Plenum, New York, 1971).

${ }^{9}$ C. J. Eckhardt and J. Merski, Surf. Sci. 37, 937 (1973).

${ }^{10} \mathrm{M}$. R. Philpott and K. Syassen have recently confirmed the presence of this structure (private communication).

${ }^{11}$ Kindly provided by Professor H. Bässler and Dr. R. R. Chance.

${ }^{12}$ H. Müller, C. J. Eckhardt, R. R. Chance, and R. H. Baughman, Chem. Phys. Lett. 50, 22 (1977).

${ }^{13}$ W. T. Simpson, J. Am. Chem. Soc. 77, 6164 (1955); M. R. Philpott, Chem. Phys. Lett. 50, 18 (1977). 